\title{
Playing to Investigate the Relationship Between Achievement and the Perception of learning
}

\author{
Stephen Boyd ${ }^{1}$, \\ ${ }^{1}$ University of Sunshine Coast, SBoyd@usc.edu.au
}

\begin{abstract}
This paper investigates the relationship between achievement and the perception of enjoyment and learning through the serious game, Playing Property.

Playing Property is an audience response game forming the basis of workshops to engage junior high students, of 13 to 15 years old, and enhance their knowledge of property investment. The investigation extends to the analysis of trends in audience response decisions from 14 workshops, conducted over three consecutive years.

Emerging findings present significant associations between enjoyment and the perception of learning. The relationship between achievement, measured in accumulated game score, and the responders' perception of enjoyment is present but less significant. Further analysis supports a deeper relationship between play and learning, one where competition and other game play attributes are more effective in engagement than point scoring or rewarding.
\end{abstract}

A more detailed evaluation may include staged testing of what may be learned and how well that learning endures, in comparison with other forms of teaching.

Keywords: Serious games, audience response, engagement, property education, learning, achievement and reward

\section{Introduction}

Whether Australian universities are in the midst of an education revolution [1] or an early stage of transformation the needs of the new student cohort are not going to be met by the current teaching model alone [2]. This presents the opportunity to refine program offerings and look to innovative means to constructively align intended learning outcomes, functional learning activities, and formative assessment to support the changing student cohorts.

Serious games present as one solution for universities aiming to support learning processes in a more playful way [3]. The benefits associated with play in education are evident in the context of emotive learning and engagement. That said, not all games are engaging and not all forms of play are considered positive or beneficial to learning.

This research investigates the relationship between achievement and the perception of enjoyment and learning through the serious game, Playing Property. Playing Property is an audience response game forming the basis of workshops to engage junior high students. At 13 to 15 years old junior high school students may be regarded a new student cohort, being the target for Australian university marketing and school engagement activities.

Achievement in the gameplay may be traced back to Space Invaders where players earned a high score and posted their initials for other players to see [4]. In Playing Property achievement is quantified as points accrued making successful investment decisions. Perception of learning is measured through audience response to questions raised at the finalisation of the activity. 
The investigation extends to the analysis of correlations and trends in audience response decisions from 14 workshops, conducted over three consecutive years.

\section{Literature review}

Games present an innovative means to engage participants, and serious games may encourage functional learning. As such this literature review briefly addresses what insights may be gained from the emerging research into serious games. The review extends to look again at the motivation inherent in the play of serious games.

\section{Serious games}

Games, the focus of this research, are activities that one engages in for amusement. Games, and play, have an established relationship with problem-based learning. Through meaningful play, Vygotsky proposes that one might 'develop abstract imaginative thinking and realize goals that they could not yet achieve in real life' [5].

In extending the definition, with reference to published research, the critical defining theme relates to games being amusing, fun, or inciting play. According to Rieber [6] and Crookall [7] play, as it relates to game design, is complex and difficult to define, yet relatively easy to observe. The benefits associated with play in education are evident in the context of emotive learning and engagement. On the other hand, Rieber concedes that not all forms of play are considered positive or beneficial and the published history of play in education resembles the debate between objectivism and constructivism [3]. In discussing interactive multimedia learning environments, Rieber asserts:

"There appear to be many advantages to seriously considering play as a dominant goal for these types of learning environments, despite the caution that all forms of play should not be considered positive or beneficial. Play also holds promise as a benchmark for evaluating interactive learning environments - those that evoke it deserve special recognition and consideration." [6], p. 55.

The complex nature of emotive learning and engagement is demonstrated in the evolution and enduring popularity of the board game Monopoly. Monopoly, on the face of it, may not appear to fit a traditional description of a serious game as one that is "aim(ing) to support learning processes in a new, more playful way" [8], p. 195. However, many games do not just appear; they evolve and are adapted. Sometimes one may even grow into a game that, when played, has the opposite affect to that intended by the creator [3]. It may be presumptuous to assume that Monopoly fed on society's negativity. On the other hand, it is equally difficult to conceive how a Quaker and Georgist could bring to life 'a game that modelled capitalism at its most ruthless' [9], p. 16 - a game where everyone loses, except one - to flourish in the isolation of the Great Depression. Nevertheless, Monopoly did 'flourish', setting a scene for ruthless play. As discussed by Axelrod, ruthless play does not imply unethical play, but rather it means 'defining victory ethically and, within that definition, devoting your efforts to winning, to playing fairly but ruthlessly' [9], p. 135).

\section{Achievement and learning}

In examining learner choices Fisher and Ford found mastery orientation and time on task to be the strongest predictors to achieve an identified knowledge learning outcome [10]. Anecdotally achievements and rewards may provide the appropriate incentive to encourage further time on task and direct the gamer to perform a task to a higher standard. That said there is no empirical evidence to suggest that achievements are effective in creating the learning outcomes [4]. According to Blair et al. "achievements in learning games may be more subtle, and more complicated, than originally thought. Simply adding individual types of achievement did not result in learning games" [4], p.55. In the study by Blair et al. a combination of achievement elements resulted in a discernable effect on learning outcomes [4].

In a research field related to serious games, gamification has been widely criticized by game designers and academics who see an over reliance on points, badges and leader boards [11], over intrinsic motivators. Seaborn and Fels make specific reference to game designer Margaret Robertson who states that such approaches mean "taking the thing that is least essential to games and representing it as the core of the experience" (Robertson 2010, cited in Seaborn and Fels) [11]. 
While acknowledging the necessity for fun, or engagement for amusement, games may enable students to gain skills and build knowledge through participatory learning [12-18]. As such games, or more specifically games designed to enhance learning, or "serious games", may be an educational tool to add engagement to traditional teaching practices, or even present as separate stand-alone learning and teaching activities.

In review of the published research, it is evident that the argument has moved beyond the question of whether games are or are not effective learning tools. The discussion is more precisely focused on what the student learns when playing a serious game [3]. Similarly, in gamified systems, few studies have empirically investigated the relationship between extrinsic and intrinsic motivators and the perception of learning [11].

\section{Method}

This research investigates the relationship between achievement and the perception of enjoyment and learning through the serious game, Playing Property. Playing Property is an audience response game forming the basis of workshops to engage junior high students, of 13 to 15 years old, and enhance their knowledge of property investment.

The investigation extends to the analysis of trends in audience response decisions from 14 workshops, conducted over three consecutive years. Due to scheduling students could attend a single session only. The association between achievement and perception of enjoyment and learning has been analyzed through correlations.

\section{Playing property}

An early variant of the Playing Property game, was designed and developed by the author in 2011. The game was created with the purpose of helping students and the public to understand property markets. Specifically, the game aims to simulate property investment on the Sunshine Coast, Queensland, Australia [3]. From the onset, it was acknowledged that the game would need to accurately reflect the movements of the respective property markets and, as such, a rigorous process was developed to collect and apply the market information [3].

In Playing Property, ruthlessness in gameplay is encouraged through player-to-player communication where students are free to assist or mislead their peers. The game instructions express the intent as: 'Buy, hold and sell Sunshine Coast property to get rich. The player who reads the markets bests wins. If your property's return goes up gain a point. If it goes down lose a point' [3]. To buy, hold and sell, players are given the chance to select from the set property asset classes. Selecting the same class year-on-year implies holding and the option of not selecting means no points are gained or lost, with the player pulling out from the property market for that term. The choice for no selection creates a sound option, in the years following the financial crisis, as players may choose to abstain and retain the gains from previous years.

To encourage more play, fun, and interaction, and ultimately to seek to enhance the players' communication skills, the game was intentionally designed to encouraged discussion and team play. The instructions for Playing Property address the interactions through noting, work as a team, chat and discuss but make your own decision [3]. In supporting the instructions, the facilitator would suggest that the players talk, share information from their own experiences, and even collaborate or collude. On the other hand, the instructions would extend further with the facilitator reminding the players that only one person could win and, as such, they may wish to bluff or pretend to make a choice opposed to their true selection. The audience response system and the response cards made it possible to deceive others as the selection results were grouped and individual scores were displayed at selected intervals only, not at each year [3]. Further, the individual player was not easily identifiable as the hidden code on the back of the response card was displayed instead of the player's name.

Following the introduction, Playing Property players are presented with the first of ten slides, each representing an annual period. In accordance with the market derived baseline [3], Playing Property commences in the game year 2001 and ends in 2013. The market selection slides share a generic format, as illustrated in Figure 1. To the left of the screen, the players could see the results from the previous year, providing them with rapid feedback on their investment choices. On the right-hand side of the screen, the selected media article provides a basis for facilitated discussion as the players make their selection. After the set time of 60 to 100 seconds the 'voting' is closed and 
the grouped preferences displayed. As illustrated in the bottom right corner, the most popular selection chosen by the cohort at the time was homes, followed by offices and shops, with no one committing to sheds.

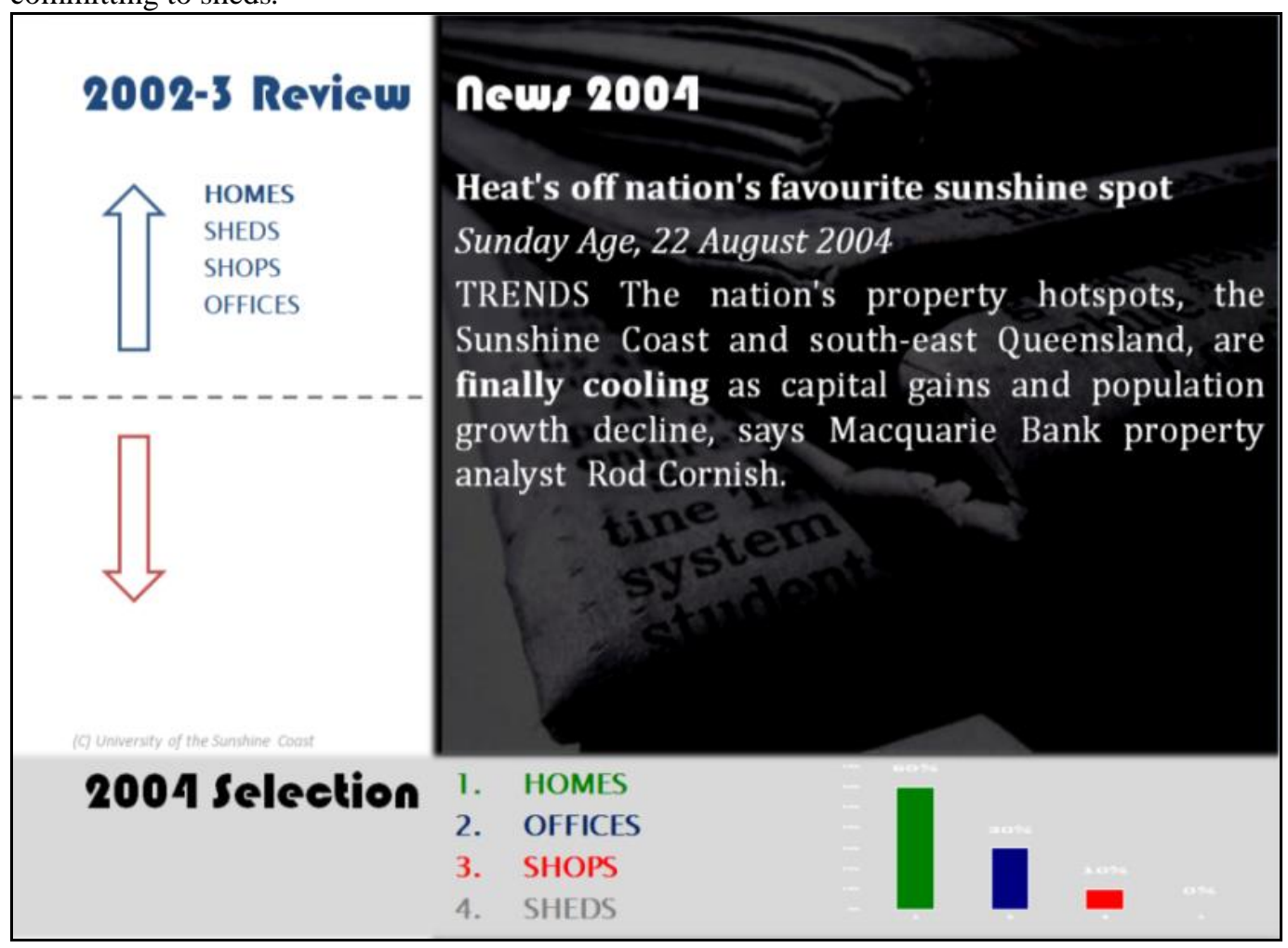

Figure 1. Playing Property game selection slide [3].

Towards the end of the game, interim scores for the top participants are presented for reference. Shortly after the presentation of interim scores, players are given the opportunity to wager, or bet, a proportion of their accumulated points on the results of the final year. In practice, the approach is like leveraging, through using another's funds to increase return, and risk, or even gambling.

After the game, final scores are shared and awards, in the form of a chocolate bar for the top three point scorers, given. As the game completes, the baseline information forming the method for allocating the points is shared and two further questions are presented. The questions were framed in a short and direct manner in an aim to avoid excessive surveying. The questions were phrased:

1. Did you enjoy playing Playing Property?

2. Did you learn more about property through playing Playing Property?

For each question, the participants could choose one of four responses, being:

1. Yes, strongly agree

2. Yes, agree

3. No, disagree

4. No, strongly disagree

The survey tool was designed with simplicity and efficiency at the core. The responses were sufficient to gauge a perception of learning but the survey was not designed to quantify learning or measure the satisfaction of learning outcomes. A student's perception of learning may be an indicator of learning and may even coincide with the achievement of learning outcomes [2-3]. That said, there are exceptions and in evaluating the effectiveness of a serious games suite Boyd uncovered instances where students observed no learning gains through gameplay but later demonstrated how the game contributed to prescribed learning outcomes. Through analyzing reflective journals, he found ".... conflict between the game player's reflections where judgement 
was made that the game did not contribute to learning, while the reflection itself demonstrated a development of knowledge or skills" [3], p. 212).

By incorporating reflective evaluation techniques and more detailed pre-and post-test surveys a deeper understanding of what is learned through gameplay may be uncovered. However, the structure of the workshops for this research provided little scope for further questioning. The students were subject to survey fatigue as they were required to answer a series of questions regarding each of the attended workshops and complete an overall experience questionnaire.

\section{Participants}

Across the three years there were 341 participants in the Playing Property workshops. The participants comprised junior high school students, of 13 to 15 years old, with a teacher and/or observer occasionally joining in.

The workshops were conducted in an equivalent manner with a common baseline. The later 2015 and 2016 versions comprised some minor amendments and the game was shortened, commencing in game year 2004.

The proportion of participants making a property asset selection varied from question-toquestion with the greatest participation, 93 percent, in game year 2003. Presumably the global financial crisis encouraged a conservative investment approach with one in five (23\%) abstaining in game year 2008 .

\section{Findings}

The evaluation discusses trends in audience response decisions along with brief survey responses from 14 workshops, conducted over three years. The IBM system, SPSS Statistics 22, has been utilized with a primary focus on the relationships between selected categorical or scale variables. The audience responses contribute to a running score or categorical points total. The final score and respective placing against fellow games has been used as a measure of achievement.

With respect to points, the students' performance broadly followed the markets. In the earlier part of the games the markets performed well with most asset classes reflecting gains. The students struggled in the game years 2010 to 2012, as the markets became more volatile. They lost points through investing in shops and offices in 2010, and then in 2011 total returns from homes and sheds declined.

When asked 'what \% of your points would you like to wager, or bet, on the last question', around one half (161) of the participants (341) chose to go "all in" with the remaining responses generally evenly spread between nil, 25 percent, 50 percent and 75 percent. The "all in" approach was fortuitous for all except those who choose sheds (industrial properties) in game year 2013.

To investigate the accrued points further exploratory data analysis has been undertaken to investigate the scale data distributions. The results of the base qualitative analyses are presented in Table 1.

Table 1. Point score frequencies 


\begin{tabular}{c|c|c}
\hline Accrued points & Interim score & Final score \\
\hline $\mathrm{N}$ & 341 & 341 \\
\hline Mean & 5.35777 & 8.85044 \\
\hline Std. Error of Mean & .149358 & .297583 \\
\hline Median & 5.00000 & 9.00000 \\
\hline Mode & 6.000 & 5.495218 \\
\hline Std. Deviation & 2.758064 & 30.197 \\
\hline Variance & 7.607 & .300 \\
\hline Skewness & .080 & .132 \\
\hline Std. Error of Skewness & .132 & -.342 \\
\hline Kurtosis & -.449 & .263 \\
\hline Std. Error of Kurtosis & .263 & 26.000 \\
\hline Range & 13.000 & -1.000 \\
\hline Minimum & -1.000 & 25.000 \\
\hline Maximum & 12.000 & \\
\hline
\end{tabular}

The introduction of the bet, or wager, had an impact on the score distributions. The interim scores reflect a more normal distribution with a lower standard deviation, variation and skewness. After the wager, the distribution had a longer right tail with some students using leveraging to maximize their final score.

After the game responses were sought to questions regarding enjoyment and learning. The questions were framed in a short and direct manner and sought feedback on the game and specifically ask the responder to rate their level of enjoyment and perception of whether they feel they have learned more about property.

The response rate was relatively high with three out of four students prepared to register whether they enjoyed the experience (262, or 77 percent) and if they felt that they learned more about property through play (269, or 79 percent). Of the responses the clear majority, 89 percent, agreed that they enjoyed the experience and 82 percent considered that they learned more about property through playing Playing Property. There was a notable higher proportion of participants who 'strongly' agreed that they enjoyed the experience, as opposed to 'strongly' agreeing that they learned about property.

As shown in the crosstabulation, Table 2, there appears to be a strong relationship between a student enjoying the game and perceiving that the learned more about property. Notably 64 respondents strongly agreed that they enjoyed playing and felt that they had learned more about property. The Pearson Chi-Square Independence supports this assertion with an association between enjoyment and perception of learned observed, with an Asymptotic Significance (2-sided) of $p=0.000$. The results of the independence analysis are presented in Table 3 .

Table 2. Audience response crosstabulation

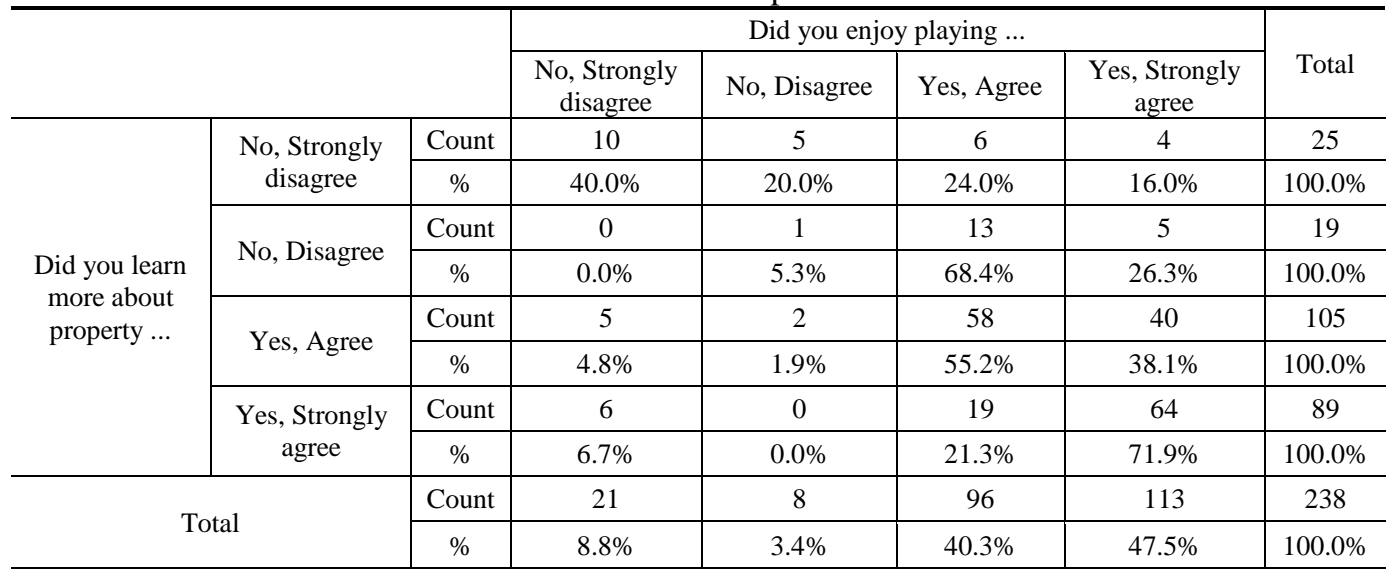

Table 3. Chi-Square Tests 


\begin{tabular}{c|c|c|c}
\hline & Value & df & Asymptotic Significance \\
& & $95.316^{\mathrm{a}}$ & .000 \\
\hline Pearson Chi-Square & 78.010 & 9 & .000 \\
\hline Likelihood Ratio & 42.601 & 1 & .000 \\
\hline Linear-by-Linear Association & 238 & & \\
\hline N of Valid Cases & a. 6 cells $(37.5 \%)$ have expected count less than 5. The minimum expected count is .64. \\
\hline
\end{tabular}

According to the heat map chart, Figure 2, there appears to be a relationship between achievement and perception of enjoyment and perception learning. The greater final score, represented in the darker shade of red, appears to coincide with the stronger perception of enjoying the game.

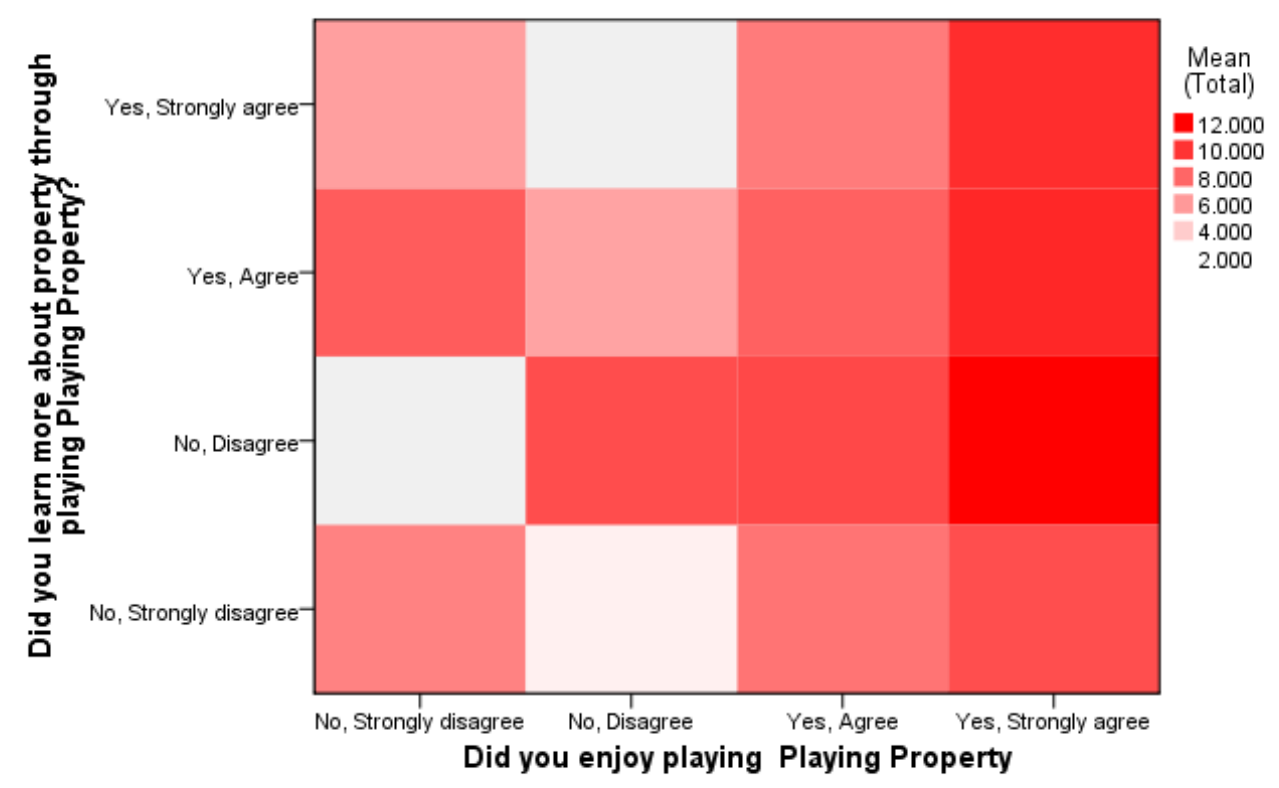

Figure 2. Heat map chart

To investigate the association between achievement and perception of enjoyment and learning further classical correlations have been analysed. The SPSS Statistics 22 has been utilized with a primary focus on the linear relationship represented in Pearson product-moment correlation coefficient. When investigating two ordinal data the Spearman rank-order correlation coefficient, or Spearman's rho, has been computed. The results of the correlation coefficient analyses are presented in Table 4. 
Table 4. Correlation coefficients

\begin{tabular}{|c|c|c|c|c|c|c|}
\hline & & Interim score & Bet & Final score & $\begin{array}{c}\text { Did you enjoy } \\
\text { playing ... }\end{array}$ & $\begin{array}{c}\text { Did you learn more } \\
\text { about property ... }\end{array}$ \\
\hline \multirow[t]{3}{*}{ Interim score } & Correlation & 1 & -.102 & $.786 * *$ & .107 & .042 \\
\hline & Sig. (2-tailed) & & .060 & .000 & .085 & .489 \\
\hline & $\mathrm{N}$ & 341 & 341 & 341 & 262 & 269 \\
\hline \multirow[t]{3}{*}{ Bet } & Correlation & -.102 & 1 & $.191 * *$ & .025 & -.040 \\
\hline & Sig. (2-tailed) & .060 & & .000 & .688 & .512 \\
\hline & $\mathrm{N}$ & 341 & 341 & 341 & 262 & 269 \\
\hline \multirow[t]{3}{*}{ Final score } & Correlation & $.786 * *$ & $.191 * *$ & 1 & $.250 * *$ & .114 \\
\hline & Sig. (2-tailed) & .000 & .000 & & .000 & .062 \\
\hline & $\mathrm{N}$ & 341 & 341 & 341 & 262 & 269 \\
\hline \multirow{3}{*}{$\begin{array}{c}\text { Did you enjoy } \\
\text { playing ... }\end{array}$} & Correlation & .107 & .025 & $.250 * *$ & 1 & $.424 * *$ \\
\hline & Sig. (2-tailed) & .085 & .688 & .000 & & .000 \\
\hline & $\mathrm{N}$ & 262 & 262 & 262 & 262 & 238 \\
\hline \multirow{3}{*}{$\begin{array}{l}\text { Did you learn more } \\
\text { about property ... }\end{array}$} & Correlation & .042 & -.040 & .114 & $.424 * *$ & 1 \\
\hline & Sig. (2-tailed) & .489 & .512 & .062 & .000 & \\
\hline & $\mathrm{N}$ & 269 & 269 & 269 & 238 & 269 \\
\hline
\end{tabular}

The analysis presents four associations that are statistically significant at the 0.01 level (2tailed). As potentially expected, the scores interim and final present a strong linear relationship. Similarly there is a correlation between the bet, or wager of tallied points, and final score. The ordinal variable relating to 'Did you learn and did you enjoy playing ...' and final score are positively correlated $(0.250)$, and the correlation is significant at the 0.01 level.

Analysing the responses from the questions yields that Pearson's correlation coefficient (0.424) is significant at the 0.01 level. The Spearman rank-order correlation coefficient presents a similar relationship $(0.421)$ at the 0.01 level. As such, there is a significant, albeit modest association between the student's enjoyment and their perception of learning in playing the game, Playing Property.

The findings present a weak linear relationship between the scores achieved in gameplay and the responders' perception of enjoyment. The analysis presents a modest association between enjoyment and perception of learning. On the other hand, there is no statistically significant relationship reflected in the final point score and perception of learning more about property.

\section{Conclusions}

A serious game was incorporated into a university workshop as the activity to engage with the junior high students and enhance their knowledge of property investment.

The findings of the audience responses, appear to support the notion that playing the game was fun and provided an opportunity to learn more about property. There is a significant association between enjoyment and perception of learning. The relationship between achievement, measured in accumulated game score, and the responders' perception of enjoyment is present but less significant. The analysis presents a modest association between enjoyment and perception of learning. On the other hand, there is no statistically meaningful relationship reflected in the final point score and perception of learning more about property.

Further analysis supports a deeper relationship between play and learning, one where competition and other game play attributes are more effective in engagement than point scoring or rewarding. As a further consideration, the achievement orientation in Playing Property has been directed toward performance in gameplay rather than learning. It would be worthwhile investigating learning oriented achievement to see if there is a stronger relationship with the perception of learning.

While the research presents significant relationships in game-enhanced learning, there remain numerous opportunities for future research to empirically confirm, or refute, the claim. This may be achieved through the analysis of a diverse range of serious games. Playing Property, was designed as a game aligned to learning property management. It followed a rigid and repetitive structure. By providing an abundance of structure, or scaffolding, the activity is at risk of becoming formatively instructional, being more objective and less conducive to knowledge construction [23]. In addition to evaluating more games, assessment items such as reflective journals may provide a greater wealth of information to form a more accurate measure of what the student has learned. 
A more detailed evaluation may include staged testing of what may be learned and how well that learning endures, in comparison with other forms of teaching. Similarly, there are established measures such as self-efficacy (VGSES), engagement (GEQ), and intrinsic motivation (IMI) that are practiced in serious games research that may assist with gaining a greater understanding of the relationships.

This paper extends the body of research investigating the relationship between extrinsic and intrinsic motivators and the perception of learning [11]. That said, the most novel and relevant extension of the research will consider how the serious game play encourages learning.

\section{References}

[1] Ernst \& Young. University of the future: a thousand year old industry on the cusp of profound change, Ernst \& Young, Australia, viewed 7 January 2014, 2012. $<$ http://www.ey.com/AU/en/Industries/Government---Public-Sector/UOF_University-of-thefuture $>$.

[2] Biggs, J., \& Tang, C. Teaching for quality learning at university: what the student does, 3rd edn, SRHE and Open University Press, Berkshire, England, 2009.

[3] Boyd, S. Playing Property - designing serious games to enhance the learning experience for undergraduate property students in Australia, doctoral thesis, University of the Sunshine Coast, Sippy Downs, Queensland, 2015.

[4] Blair, L., Bowers, C., Cannon-Bowers, J., \& Gonzalez-Holland, E. Understanding the Role of Achievements in Game-Based Learning, International Journal of Serious Games, vol. 3, iss. 4, pp.47-56, December 2016. https://doi.org/10.17083/ijsg.v3i4.114

[5] Young, M., Slota, S., Cutter, A., Jalette, G., Mullin, G., Lai, B., Simeoni, Z., Tran, M., \& Yukhymenko, M. Our princess is in another castle: a review of trends in serious gaming for education, Review of Educational Research, vol. 82, no. 61, 2012. <http://rer.sagepub.com/content/82/1/61>. https://doi.org/10.3102/0034654312436980

[6] Rieber, L. Seriously considering play: designing interactive learning environments based on the blending of microworlds, simulations, and games, Educational Technology Research and Development, vol. 44, no. 2, pp. 43-58, 1996. https://doi.org/10.1007/BF02300540

[7] Crookall, D. Serious games, debriefing, and simulation/gaming as a discipline, Simulation \& Gaming, vol. 41, no. 6, pp. 898-920, 2010. https://doi.org/10.1177/1046878110390784

[8] Poplin, A. Games and serious games in urban planning: study cases, Computational Science and Its Applications - ICCSA 2011, Proceedings International Conference, Santander, Spain, 20-23 June 2011, Part II, pp. 1-14, 2011.

[9] Axelrod, A. Everything I know about business I learned from Monopoly®: successful executive strategic lessons learned from the world's greatest board game, Running Press, Philadelphia, Pennsylvania, 2002.

[10] Fisher, S., \& Ford, K. Differential Effects of Learner Effort and Goal Orientation on two Learning Outcomes, Personnel Psychology, vol. 51, pp.397-420, 1998. https://doi.org/10.1111/j.1744-6570.1998.tb00731.x

[11] Seaborn, K., \& Fels, D. Gamification in theory and action: A survey, International Journal of Human-Computer Studies, vol. 74, pp.14-31, 2015. https://doi.org/10.1016/j.ijhcs.2014.09.006

[12] Crawford, C. The art of computer game design, McGraw-Hill/Osborne, Berkeley, California, 1984.

[13] Gee, J., Reflections on empirical evidence on games and learning, in Tobias, S. and Fletcher, J. (eds), Computer games and instruction, Information Age Publishing, Charlotte, North Carolina, pp. 223-232, 2011.

[14] Klopfer, E., Osterweil, S., \& Salen, K. Moving learning games forward - obstacles opportunities and openness, Education Arcade Creative Commons, Massachusetts Institute of Technology, Cambridge, Massachusetts, 2009.

[15] Egenfeldt-Nielsen, S. Third generation educational use of computer games, Learning and Teaching with Electronic Games, AACE, Chesapeake, Virginia, pp. 262-281, 2009.

[16] Johnson, L., Adams Becker, S., Estrada, V., \& Freeman, A. NMC horizon report: 2014 higher education edition, New Media Consortium, Austin, Texas, 2014. 
[17] Wu, W., Chioub, W., Kao, H., Hu, C., \& Huang, S. Re-exploring game-assisted learning research: the perspective of learning theoretical bases, Computers \& Education, vol. 59, no. 4, pp. 1153-1161, 2012. https://doi.org/10.1016/j.compedu.2012.05.003

[18] Connolly, T., Boyle, E., MacArthur, T., \& Boyle, J. A systematic literature review of empirical evidence on computer games and serious games, Computers \& Education, vol. 59, pp. 661-686, 2012. https://doi.org/10.1016/j.compedu.2012.03.004

[19] Cain, J., Black, E., \& Rohr, J. An audience response system strategy to improve student motivation, attention, and feedback, American Journal of Pharmaceutical Education, vol. 73, no. 2, article 21, pp. 1-7, 2009.

[20] Medina, M., Medinam P., Wanzer, D., Wilson, J., Er, N., \& Britton, M. Use of an audience response system (ARS) in a dual-campus classroom environment, American Journal of Pharmaceutical Education, vol. 72, no. 2, article 38, pp. 1-7, 2008. 